\title{
Effect of ageing treatment on microstructure and stress corrosion cracking of an Al-4.2Zn-1.6Mg alloy
}

\author{
Kezhun $\mathrm{He}^{1}$, Ling Meng ${ }^{1}$, Xingwei Xie ${ }^{1}$, Yongkang Le ${ }^{1}$, Wenbiao Zhou ${ }^{2}$ \\ ${ }^{1}$ Alnan Aluminum Incorporation, Nanning 530031, China \\ ${ }^{2}$ The College of Materials Science and Engineering, Beijing University of Technology, Beijing \\ 100124, China
}

Keywords: Al-Zn-Mg, ageing, stress corrosion cracking, precipitate, microstructure.

\begin{abstract}
The effect of T4, T6, T77 and T73 ageing treatments on microstructure and stress corrosion cracking of an Al-4.2Zn-1.6Mg alloy was investigated. TEM study revealed that there is no $\eta$ ' phase on the matrix or grain boundary in the T4 sample, and the precipitates on the grain boundaries of the T6 sample were small and continuously distributed, while the precipitates of the T77 and T73 samples discontinuously distributed on the grain boundary. Stress corrosion cracking resistance test in in the $50^{\circ} \mathrm{C} 3.5 \% \mathrm{NaCl}$ solution and fractured surface observation revealed that the T4 sample have higher tendency of stress corrosion cracking compared with that of the T6 sample, while the T77 and T73 samples show good resistance of stress corrosion cracking. It is worth to note that the strength of the T77 sample is very close to that of the T6 sample.
\end{abstract}

\section{Introduction}

Excellent formability and good weldability, make medium strength Al-Zn-Mg alloys extensively used in the aerospace and transportation vehicles as structural components [1-2]. Most studies revealed that the hardening effect of $\mathrm{Al}-\mathrm{Zn}-\mathrm{Mg}-(\mathrm{Cu})$ alloys could be attributed to the fine and uniformly distributed precipitates $\eta^{\prime}\left(\mathrm{MgZn}_{2}\right)$ phase in the matrix which form during artificial ageing [3-4]. However, these high strength $\mathrm{Al}-\mathrm{Zn}-\mathrm{Mg}-(\mathrm{Cu})$ alloys are susceptible to stress corrosion cracking (SCC) which may causes service failures in the aerospace industry. Although the SCC mechanism is not completely understood in these alloys, many efforts have been made to correlate the microstructure with the SCC behavior of the alloys. The major microstructural features that affect the SCC resistance are grain boundary precipitate, matrix precipitation phase (MPT) and precipitate free zone (PFZ).It is well documented that over ageing can be used to improve the SCC susceptibility of Al-Zn-Mg- $(\mathrm{Cu})$ alloy in the industrial practice but reduce the strength of alloys by $10-15 \%$ compared to the peak ageing (T6) temper due to matrix precipitates growth [5].

In this paper, the effect of T4, T6 T77 and T73 ageing treatments on microstructure, tensile properties and stress corrosion cracking of an $\mathrm{Al}-4.2 \mathrm{Zn}-1.6 \mathrm{Mg}$ alloy was studied.

\section{Experiment}

The nominal chemical composition of the $\mathrm{Al}-\mathrm{Zn}-\mathrm{Mg}(7020)$ alloy was given in Table 1 . The alloy was industrially fabricated in Alnan Aluminium Incorparation. A slab with $520 \mathrm{~mm} \times$ $1620 \mathrm{~mm} \times 5000 \mathrm{~mm}$ dimension was cast and homogenized at $470^{\circ} \mathrm{C}$ for $24 \mathrm{~h}$, followed by air cooling to room temperature. After scalped, the slab was preheated to $410^{\circ} \mathrm{C}$ and hot rolled to plate with $10 \mathrm{~mm}$ thickness. Solution heat treatment was performed at $470^{\circ} \mathrm{C}$ and followed by water quenching. The plate was sawed into several pieces and aged with various tempers given in Table 2 .

Table 1 Nominal chemical composition of investigated alloy (mass fraction, \%)

\begin{tabular}{ccccccc}
\hline Alloy & $\mathrm{Zn}$ & $\mathrm{Mg}$ & $\mathrm{Mn}$ & $\mathrm{Cr}$ & $\mathrm{Zr}$ & $\mathrm{Al}$ \\
\hline 7020 & 4.2 & 1.6 & 0.20 & 0.25 & 0.10 & Balance \\
\hline
\end{tabular}


Table 2 Ageing parameters of investigated alloy

\begin{tabular}{cc}
\hline Temper & Ageing treatment \\
\hline T4 & Natural ageing \\
T6 & $120^{\circ} \mathrm{C} \times 24 \mathrm{~h}$ \\
T77 & $120^{\circ} \mathrm{C} \times 3 \mathrm{~h}+180^{\circ} \mathrm{C} \times 1 \mathrm{~h}+120^{\circ} \mathrm{C} \times 24 \mathrm{~h}$ \\
$\mathrm{~T} 73$ & $120^{\circ} \mathrm{C} \times 3 \mathrm{~h}+175^{\circ} \mathrm{C} \times 10 \mathrm{~h}$ \\
\hline
\end{tabular}

Room temperature tensile test bars with $10 \mathrm{~mm}$ in diameter and $50 \mathrm{~mm}$ in gage length were machined according to the standard of ASTM B557-06. A ZWICK testing machine was used for the tensile test at a constant crosshead speed of $1 \mathrm{~mm} / \mathrm{min}$. The tensile property data for each condition was the average from the measurements of four specimens.

The stress corrosion cracking resistance was evaluated using SSRT according to HB 7235. The samples were tested in $50^{\circ} \mathrm{C}$ air and $50^{\circ} \mathrm{C} 3.5 \mathrm{wt} \% \mathrm{NaCl}$ solution with a strain rate of $1 \times 10^{-6} \mathrm{~s}^{-1}$ on a slow strain rate tensile machine. The gauge sections of the SSRT specimens were completely immersed in the corrosion solution by sealing with an epoxy resin when tested in $\mathrm{NaCl}$ solution.

The metallographic samples were ground and polished following standard metallographic practices. The microstructure was examined in a scanning electron microscope (SEM) type ZEISS EVO. The fracture surfaces of the samples after SSRT were observed by SEM. The GB and matrix microstructures of the samples were observed by transmission electron microscopy (JEM 2100).

\section{Result and discussion}

The bright field TEM images viewed near [111] Al from samples of various tempers are shown in Fig.1. It can be seen in Fig.1 (a) that except some globular dispersoids distribute in the matrix, there is no $\eta$ 'phase on the matrix or grain boundary in the T4 sample. EDS analysis revealed that the composition of the fine dispersoids close to $\mathrm{Al}_{3} \mathrm{Zr}$. In Fig. 1 (b) it can be found that the precipitates on the grain boundaries of the T6 sample were small and continuously distributed, and high density of nanoscale disc-shaped precipitates, about $3-5 \mathrm{~nm}$ in diameter, are homogeneously distributed throughout the matrix. Fig.1(c) displays the bright field TEM image of sample treated with T77 temper, it can be seen from the figure that the precipitates discontinuously distributed on the grain boundary, while the size of the precipitates in the matrix are similar to that of the precipitates in the sample with T6 temper. Fig.1(d) provides the bright field TEM image of sample treated with T73 temper, it can be seen obviously that the size of the precipitates in the matrix grow remarkably to diameter of $8-14 \mathrm{~nm}$ with the decreased of particle density.

Tensile property of the samples treated with various temper are shown in table 3 . It can be seen from table 3 that yield strength of sample treated withT4 temper is low compare with that of the other tempers, while its ultimate tensile strength (UTS) is the highest. Tensile strength of the sample treated withT77 temper is very close to that of the T6 temper. On the other hand, the tensile strength drops remarkably when the sample was over-aged with T73 temper.

Conductivity and $\mathrm{I}_{\mathrm{SSRT}}$ factor of the samples treated with various temper are also shown in table 3. On contrary to the highest UTS, the T4 sample has the lowest conductivity and highest ISSRT factor. It is worth to note that conductivity of the T77 sample is higher than that of the T6 sample, while the $\mathrm{I}_{\text {SSRT }}$ factor is quite low. It can be expected that the over-aged sample with T73 temper has the highest conductivity.

Fig. 2 presents the typical tensile fracture surfaces of the T4, T6, T77 and T73 samples tested in the $50{ }^{\circ} \mathrm{C} 3.5 \% \mathrm{NaCl}$ solution. As can be seen from Fig.2 (a) that the fracture surface of the $\mathrm{T} 4$ sample was dominated by cleavage facet showing the typical brittle fracture, which reveals severe stress corrosion cracking. Fig. 2 (b) depicts the fracture surface of the T6 sample, some cleavage facet can be observed on the edge of the sample. In contrast, the fracture surface of the T77 and T73 samples were dominated by small dimples which reveals ductile fracture. 

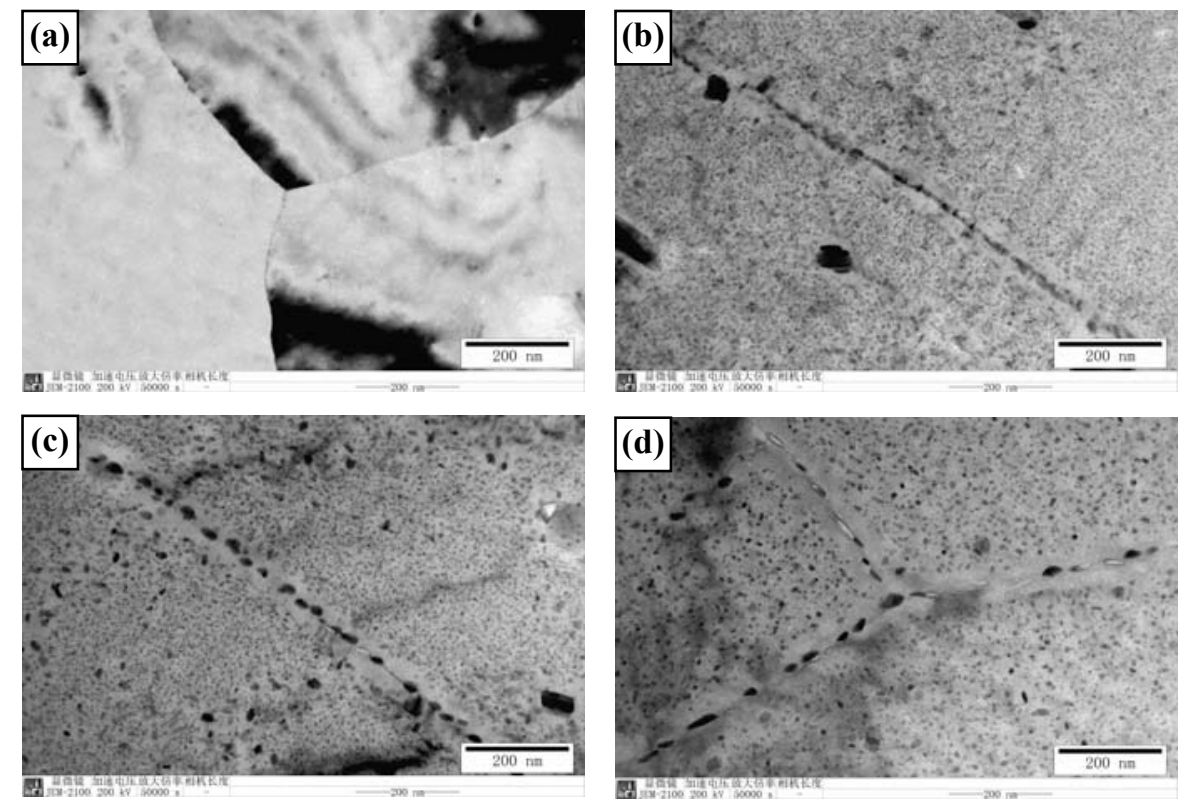

Fig.1 Bright field TEM images viewed near [111] Al from 7020 samples with various tempers: (a) T4; (b) T6; (c) T77; (d) T73

(b)

Table 3 Tensile property, Conductivity and ISSRT factor of 7020 samples with various tempers

\begin{tabular}{|c|c|c|c|c|c|}
\hline Temper & $\begin{array}{c}\text { Yield Strength } \\
\text { (MPa) }\end{array}$ & $\begin{array}{c}\text { Ultimate } \\
\text { Tensile } \\
\text { Strength (MPa) }\end{array}$ & $\begin{array}{c}\text { Elongation } \\
(\%)\end{array}$ & $\begin{array}{c}\text { Conductivity } \\
\text { (IACS\%) }\end{array}$ & $\begin{array}{c}\text { ISSRT } \\
(\%)\end{array}$ \\
\hline T4 & 303 & 433 & 13.5 & 33.7 & 15 \\
\hline T6 & 363 & 418 & 19.0 & 36.5 & 12 \\
\hline T77 & 351 & 414 & 19.5 & 38.2 & 3 \\
\hline T73 & 320 & 383 & 20.0 & 39.3 & 4 \\
\hline
\end{tabular}
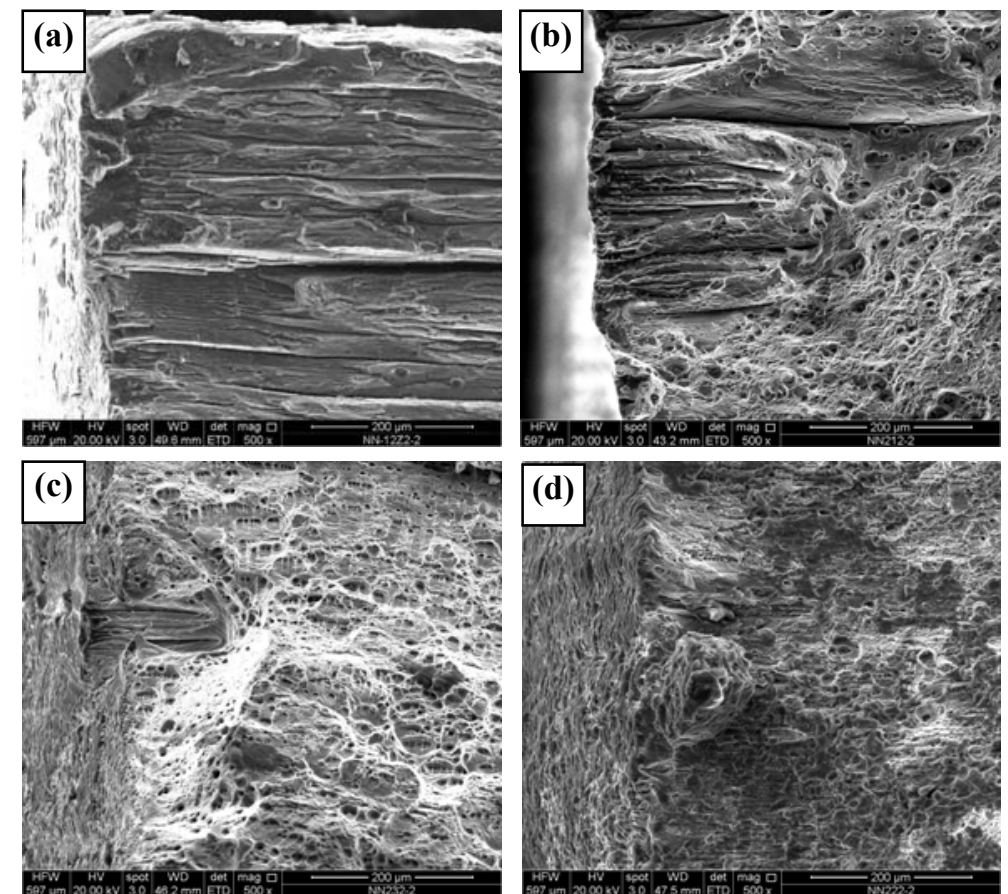

Fig.2 Fracture surfaces of 7020 samples with various tempers in $50^{\circ} \mathrm{C} 3.5 \% \mathrm{NaCl}$ solution:

T4; (b) T6; (c) T77; (d) T73

For the $\mathrm{Al}-\mathrm{Zn}-\mathrm{Mg}-(\mathrm{Cu})$ alloys, the $\mathrm{SCC}$ resistance was related to the grain boundary precipitate, matrix precipitation phase and precipitate free zone. The mechanism of the SCC in the $\mathrm{Al}-\mathrm{Zn}-\mathrm{Mg}-\mathrm{Cu}$ alloys was thought to be both anodic dissolution and hydrogen embrittlement [6]. The 
SCC resistance tests evaluated that the $\mathrm{T} 4$ and $\mathrm{T} 6$ samples had relative higher $\mathrm{I}_{\mathrm{SSRT}}$ factors, and the fracture surfaces of these samples in the $50^{\circ} \mathrm{C} 3.5 \% \mathrm{NaCl}$ solution reveal severe stress corrosion cracking, these could be ascribed to no $\eta^{\prime}$ phase on the matrix or grain boundary in the T4 sample and continuously distribution of the precipitates on the grain boundaries of the T6 sample. On the contrary, the ISSRT factor and tendency of stress corrosion cracking gradually decrease in the T73 and T77 samples, these could be attributed to the discontinuously distribution of the precipitates on the grain boundaries in the T73 and T77 samples.

\section{Summary}

Based on the TEM observations and SCC resistance tests, the following conclusions can be drawn:

The T4 and T6 samples show relative higher ISSRT factors, and the fracture surface of these samples in the $50^{\circ} \mathrm{C} 3.5 \% \mathrm{NaCl}$ solution reveal severe stress corrosion cracking.

The tensile property of the T77 sample is close to that of the T6 sample, while the ISSRT factor decrease obviously compared with that of the T4 and T6 samples. The precipitates on the grain boundaries of the T77 sample were discontinuously distributed.

The tensile strength of the over-aged T73 sample drops remarkably, the size of the precipitates in the matrix increased obviously compared with that of the T6 and T77 samples.

\section{Acknowledgement}

The authors gratefully acknowledge the support of the international science \& technology cooperation of the state under grants Nos. 2014DFA50210.

\section{References}

[1] Srivatsan TS, Anand S, Vasudevan VK. The high-cycle fatigue and fracture behavior of aluminum alloy 7055. Mater. Sci. Eng. A. 281(2000)1, 292-304.

[2] Nakai M, Eto T. New aspects of development of high strength aluminum alloys for aerospace applications. Mater. Sci. Eng. A. 285(2000)1,62-68.

[3] Stiller K, Warren PJ, Hansen V, et al. Investigation of precipitation in an Al-Zn-Mg alloy after two-step ageing treatment at $100^{\circ}$ and $150^{\circ}$ C. Mater. Sci. Eng. A. 270(1999)1, 55-63.

[4] Engdahl T, Hansen V, Warren PJ, et al. Investigation of fine scale precipitates in $\mathrm{Al}-\mathrm{Zn}-\mathrm{Mg}$ alloys after various heat treatments. Mater. Sci. Eng. A. 327(2002)1, 59-64.

[5] M Dixit, R.S. Mishra, K.K. Sankaran. Structure-property correlations in Al 7050 and Al 7055 high-strength aluminum alloys. Mater. Sci. Eng. A. 478(2008)1, 163-172.

[6] D. Najjar, T. Magnin, T.J.Warner. Influence of critical surface defects and localized competition between anodic dissolution and hydrogen effects during stress corrosion cracking of a 7050 aluminium alloy. Mater. Sci. Eng. A. 238(1997)2, 293-302. 